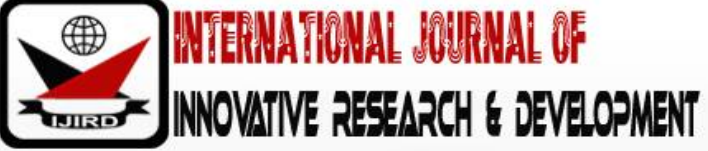

ISSN 2278 - 0211 (Online)

\section{Development and Evaluation of a Power Weeder}

\author{
Akintade J. 0. \\ Chief Lecturer, Department of Mechanical Engineering, \\ Federal Polytechnic Ilaro, Nigeria \\ Adenigba A. A. \\ Assistant Lecturer, Department of Agricultural and Bio-Environmental Engineering, \\ Federal Polytechnic Ilaro, Nigeria
}

\begin{abstract}
:
Mechanical intervention in crop production is increasing rapidly in Nigeria. Researchers are finding ways to manage weeds in farms using suitable mechanical devices instead of conventional hand weeding and chemical control. This study was conducted to design, fabricate and evaluate the field performance of a power weeder. The weeder was evaluated at "Idogo" farm settlement which is located in "Ilaro" community, Ogun state. The variety of cassava on the farm was TMS 30572 (145 days) which was planted at non-uniform inter and intra row spacing. Field performance parameters such as speed of operation, effective field capacity, field efficiency, weeding efficiency, plant damage and fuel consumption were observed to be $0.28 \mathrm{~m} / \mathrm{s}, 0.03 \mathrm{hah}^{-1}, 97.3 \%, 89 \%, 15.02 \%$ and $0.264 \mathrm{lh}^{-1}$ respectively. The soil moisture content of the farm was determined on dry basis $(18 \% \mathrm{db})$ while the soil bulk density was also determined before and after weeding, the bulk densities are $1.31 \mathrm{gm} / \mathrm{cm}^{3}$ and $1.22 \mathrm{gm} / \mathrm{cm}^{3}$ respectively. The weeder worked effectively with very little emission of smoke from the engine exhaust and its fuel consumption is minimal, this shows that the weeder is economic, easy and also environmentally safe weed control device.
\end{abstract}

Keyword: Speed of operation, effective field capacity, field efficiency, weeding efficiency, plant damage, fuel consumption

\section{Introduction}

Weed control is one of the most important tasks that accounts for a considerable share of the costs involved in agricultural production. Among the control methods are mechanical, chemical, biological and cultural (Biswas, 1984). The mechanical control of weeds is most widely used; it is the simplest method of weed control being followed by man since agriculture came into practice (Vinod, 2002). The chemical method involves scientific knowledge on the subject and the health hazards involved scares some of our traditional farmers coupled with the cost. Today the agricultural sector requires non-chemical weed control that ensures food safety. Consumers demand high quality food products and pay special attention to food safety. Through the technical development of mechanisms for physical weed control, such as precise inter-and intra-row weeder, it might be possible to control weeds in a way that meets consumer and environmental demand. Uncontrolled weeds growth reduces yield of the principal crops while untimely weeding reduces the returns from the overall investments in the production of crops. Weeds accounts for about $50-70 \%$ reduction in yield; particularly in the humid tropics where torrential rainfall significantly interrupt work on the farms in the season (Rangsamyet al. 1993). The situation necessitates the introduction of an appropriate machine for effective weed control. It is reported that manual weeding is labour-intensive, accounting for about $80 \%$ of the total labour required for producing food in Nigeria (Vinod, 2002). Farmers using only hand hoe for weeding would find it difficult to escape poverty, since this level of technology tends to perpetuate human drudgery, risk and mystery. Mechanical weed control is effective in controlling weeds as well as it benefits the crop by breaking up the surface crust, aeration of soil, stimulating the activity of soil microflora, reducing the evaporation of soil moisture and facilitating the infiltration of rainwater. In order to reduce the drudgery involved in weeding operation and non-availability of labour, assert the necessity for the introduction of power weeder. Evaluation of the power weeders are of peak importance to reduce the considerable strain to the operator involved in the weeding operation.

\section{Materials and Methods}

The weeder was evaluated at "Idogo" farm settlement which is located in "Ilaro" community, Ogun state. The variety of cassava on the farm was TMS 30572 (145 days) which was planted at non-uniform inter and intra row spacing.

\subsection{Power Requirement}

Soil resistance has a considerable effect upon the power requirements of weeders. Also, the width and speed of cut of operation influences the power requirements of the weeder. Assumptions;

$\mathrm{S}_{\mathrm{r}}$ is soil resistance, $0.7 \mathrm{~N} / \mathrm{m}^{2}$, $\mathrm{d}$ is maximum depth of cut, $7 \mathrm{~cm}$ 
$\mathrm{W}$ is maximum width of cut, $\mathrm{cm} 35, \mathrm{~V}$ is speed (maximum) of operation, $0.5 \mathrm{~m} / \mathrm{s}$

$$
\mathrm{p}_{\mathrm{r}}=\frac{\mathrm{Sr \times d \times \textrm {w } \times \mathrm { v }}}{75} \text { (Vinod, 2002) }
$$

2.1.1. Determination of the Transmission Efficiency

$$
\begin{aligned}
& \mathrm{P}_{\mathrm{t}}=\frac{P r}{\epsilon} \quad(\text { Vinod, 2002) } \\
& \epsilon=\frac{1.14}{1.49}=0.765
\end{aligned}
$$

The transmission efficiency of the weeder is $76.5 \%$

Where; $P_{r}$ is power required to dig the soil, $\epsilon$ is the transmission efficiency of the weeder. Hence a prime mover of $1.49 \mathrm{kw}$ ( $2 \mathrm{hp})$ is required.

\subsubsection{Determination of Torque Transmitted by the Shaft}

$$
\mathrm{T}=\frac{\mathrm{P} \times 60 \times 10^{3}}{2 \times \pi \times \mathrm{N}} \text { (Khurmi.,2012) }
$$

Where $\mathrm{P}$ is power in $\mathrm{Kw}, \mathrm{T}$ is torque transmitted by the shaft $(\mathrm{Nm})$, Assuming engine speed is $6500 \mathrm{rpm}$ and engine power $1.49 \mathrm{Kw}$

$$
\mathrm{T}=\frac{1.49 \times 60 \times 10^{3}}{2 \times 3.142 \times 6500}=2.18 \mathrm{Nm} .
$$

\subsection{Effective Weeding Area}

Total length of the weeder head (Wt.) is $35 \mathrm{~cm}$., Length of rotor drive system(RL) is $6 \mathrm{~cm}$.

Weeding length (frame) $=$ Wt. $-\mathrm{R}_{\mathrm{L}}=35-6=29$

Diameter of the weeder (frame) is $16.5 \mathrm{~cm}$

Effective weeding area $=2 \pi r \times 29$

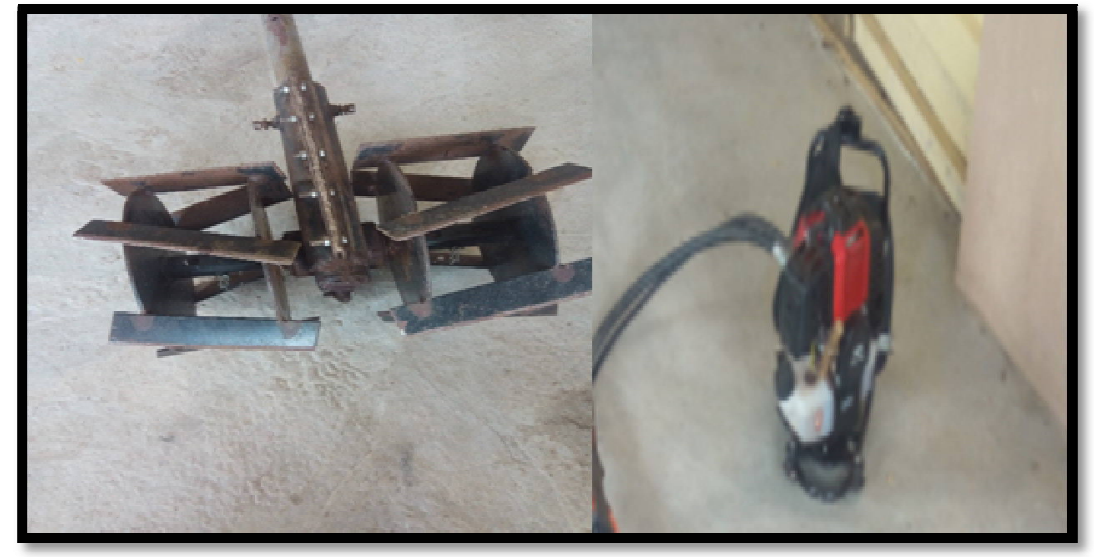

Figure 1: The Weeding Blade, Driving Rotor and 2 Stroke Engines

\subsubsection{Determination of Spacing between Blades}

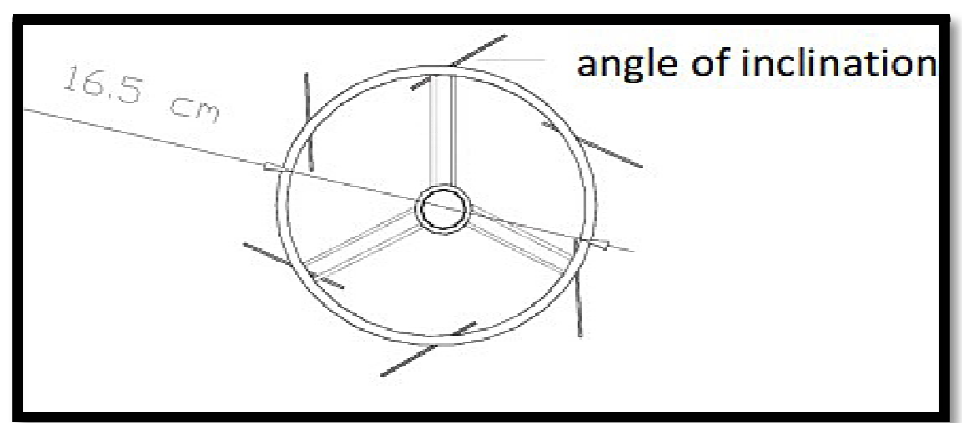

Figure 2: Weeding Frame Diameter Specification and Blade Inclination

Circumference of the blade frame is $2 \pi r=\pi d$

Total width of blade $\left(\mathrm{T}_{\mathrm{W}}\right)$ is the width of one blade multiply by the numbers of blade on each working frame.

$$
\text { Spacing between blades }=\frac{\pi d-T w}{\text { numbers of blade }}
$$

Where $d$ is the diameter of the frame $(16.5 \mathrm{~cm}), \pi$ is a constant (3.142) 
The circumference is thus calculated as; $3.142 \times 16.5=51.836 \mathrm{~cm}$

Number of blades in half of a working set is $5, \mathrm{~Wb}$ is the width of a blade $(5.51 \mathrm{~cm})$

$5.51 \mathrm{~cm}$

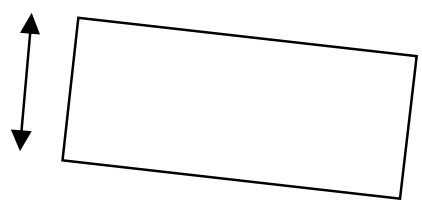

Total space occupied by blades is $5.51 \times 5=27.55 \mathrm{~cm}$

Total spacing between blades is $51.836-27.55=24.286 \mathrm{~cm}$

Spacing between two blades is $\frac{24.286}{5}=4.86 \mathrm{~cm}$

The technical specifications of power paddy weeder is shown in Table 1 Bellow

Table 1. Technical specification of the Power Weeder

\begin{tabular}{|c|c|c|}
\hline $\sin$ & item & specification \\
\hline 1 & Weight kg & $15 \mathrm{~kg}$ \\
\hline 2 & Vertical height cm & $188 \mathrm{~cm}$ \\
\hline 3 & Width cm & $35 \mathrm{~cm}$ \\
\hline 4 & \multicolumn{2}{|c|}{ prime mover } \\
\hline Type of engine & \multicolumn{2}{|c|}{ Two stoke single cylinder forced air cooled petrol engine } \\
\hline & Power & $1.5 \mathrm{~h} p$ \\
\hline & Rated speed & $6500 \mathrm{rpm}$ \\
\hline Torgue & \multicolumn{2}{|c|}{$2.18 \mathrm{Nm} @ 6500 \mathrm{rpm}$} \\
\hline & Carburettor & Diaphragn type \\
\hline & Starting & Recoil start \\
\hline 5 & \multicolumn{2}{|l|}{ Drive } \\
\hline Clutch & \multicolumn{2}{|c|}{ Centrifugal expanding type } \\
\hline & Gear teduction & Worm gear type reduction of \\
\hline \multirow[t]{7}{*}{$20: 16$} & \multicolumn{2}{|c|}{ w eed ing rotor } \\
\hline & Type of weeder & Rotary \\
\hline & Blade shape & Rectangular \\
\hline & Number of blades per section & 5 \\
\hline & Row spacing & Adjustable (maximum $35 \mathrm{~cm})$ \\
\hline & Skid dimension of blade $(\mathrm{L} \times \mathrm{B})$ & $(5.51 \times 14.5) \mathrm{cm}$ \\
\hline & Angle of blade inclination & $35^{?}$ \\
\hline
\end{tabular}

Table 1: Technical Specification of the Power Weeder

\subsection{Speed of Operation $\mathrm{Ms}^{-1}$}

To determine the speed of operation, lengths of $5 \mathrm{~m}, 10 \mathrm{~m}$, and $15 \mathrm{~m}$ were marked out in four replicates with pegs and strings. The machine was operated along the marked-out length and a stopwatch was used to record the time taken by the machine to simultaneously move and weed along the marked-out points. The speed of travel of the machine was completed in $\mathrm{m} / \mathrm{s}$. 


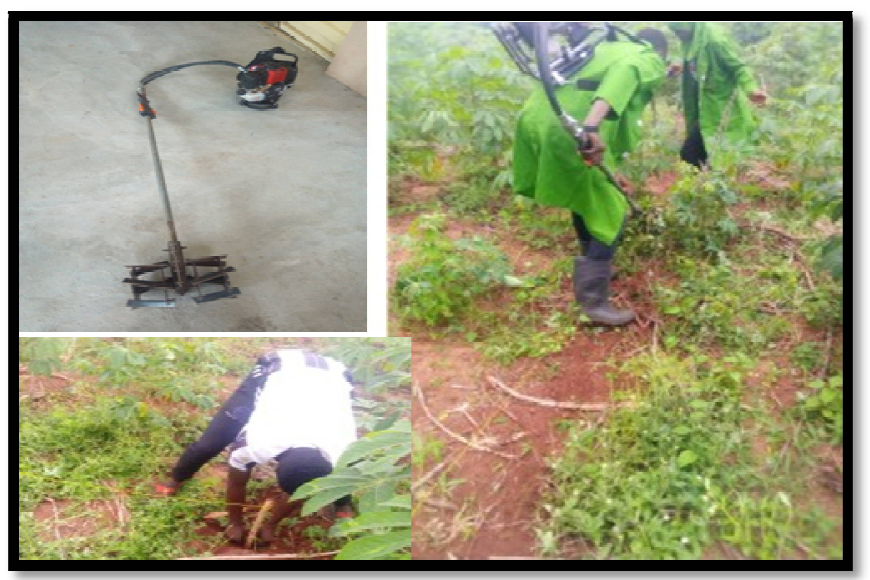

Figure 3: Marking Out and Weeding Operation

\subsection{Theoretical Field Capacity Hah-1}

Theoretical field capacity is the rate of field coverage of the machine based on $100 \%$ time at the rated speed and covering $100 \%$ of it rated width. The Theoretical Field Capacity was determined by the following relationship (Chanakyan and Mohanty 2017).

Theoretical Field capacity hah ${ }^{-1}=\frac{\text { width }(\mathrm{m}) \times \operatorname{speed}\left(\frac{\mathrm{km}}{\mathrm{h}}\right)}{10}$

\subsubsection{Effective Field Capacity Hah-1}

Effective field capacity was measured by the actual area covered by the machine, based on its total time consumed. Plots of $5 \mathrm{~m}^{2}$ was marked out in four replicates within the farm and the effective field capacity was determined by the following relationship (Chanakyan and Mohanty 2017)

Effective field capacity $=\frac{\text { total area covered,ha }}{\text { total time taken }, \mathrm{h}}$

\subsubsection{Field Efficiency, $\%$}

Field efficiency is the ratio of effective field capacity to the Theoretical field capacity. It was determined by using this formula, (Chanakyan and Mohanty 2017)

Field Efficiency, \% $=\frac{\text { effective field capacity,ha/ } \mathrm{h}}{\text { theoretical field capacity,ha } / \mathrm{h}} \times 100$

\subsection{Fuel Consumption Lha-1}

The fuel consumption was measured by the top filled method. The fuel tank of the machine was filled at its full capacity before starting the engine. The machine was run at a constant speed within a $50 \mathrm{~m}^{2}$ plot which has been marked out on the cassava farm. After the completion of the weeding operation, the fuel was refilled in the tank up to the top level. The quantity of refilled fuel was measured with a measuring cylinder, this observation was used to determine the fuel consumption in Lh-1 and Lha ${ }^{-1}$.

\subsection{Weeding Efficiency, \%}

Is the ratio of number of weeds removed after weeding to the number of weeds present before weeding. Strings and pegs were used to mark out squares of $\left(1 \mathrm{~m}^{2}\right)$ which were randomly placed on the field and the number of weeds was counted before and after weeding. The weeding efficiency of each of the three $1 \mathrm{~m}^{2}$ plots was determined using the following formula,

Weeding efficiency, $\%=\frac{w 1-w 2}{w 1} \times 100$

Where $\mathrm{W}_{1}$ is weeds before weeding in $1 \mathrm{~m}^{2}$ area, $\mathrm{W}_{2}$ is weeds after weeding in $1 \mathrm{~m}^{2}$ area (Chanakyan and Mohanty 2017). The average weeding efficiency for the three plots was computed as the weeding efficiency of the machine.

\subsection{Plant Damage, $\%$}

Plant damage is a ratio between the number of plant damage in a row after weeding to the number of plant available before weeding (Saiful et al., 2015). It was determined by counting the total number of plants within the four marked out plot of equal size $\left(5 \mathrm{~m}^{2}\right)$ before weeding. The total number of damaged plant and the plant which were totally removed by the machine was counted.

Plant damage, $\%=\frac{q}{p} \times 100$

Where $\mathrm{q}$ is number of plants damaged/ removed within the $5 \mathrm{~m}^{2}$ plot after weeding, $\mathrm{P}$ is number of plants available before weeding 


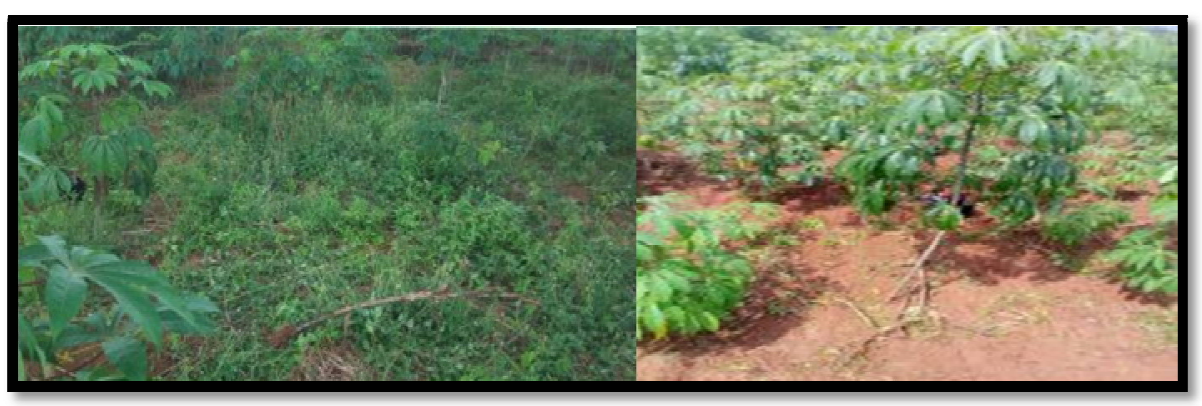

Figure 4: Before and after Weeding Operation

\subsection{Moisture Content}

Some portions of soil samples were collected from the $50 \mathrm{~m}^{2}$ plot. The soil sample were collected in cylinders of known volume at different points within the plot before and after weeding. The soil samples were used to determine the plot moisture content and bulk density.

The soil samples collected was subjected to drying in an oven for 8 hours and the moisture content of the soil samples were determined on dry basis.

Moisture content $=\frac{w t-w d}{w d} \times 100$

Moreover, the soil samples after oven drying were also used to determine the bulk density which helps to illustrate the compatibility effect of the power weeder on the soil during weeding operation.

Bulk density $=\frac{\text { mass }}{\text { volume }}$

\section{Result and Discussion}

The performance evaluation of the power weeder was thoroughly carried out and the results shows the weeder was effective in performing weeding operation without causing much damage to the crops.

\subsection{Determination of Speed in $\mathrm{Ms}^{-1}$}

The result shown in table1 and 4 depicts that the speed of operation of the machine is not significantly affected by the distance covered during operation and the area covered during weeding. The highest average speed of operation recorded is $0.28 \mathrm{~ms}^{-1}$ at $5 \mathrm{~m}$ length of operation, there is a reduction in speed at $10 \mathrm{~m}$ length of operation to $0.23 \mathrm{~ms}^{-1}$ and a subsequent increase to $0.25 \mathrm{~ms}^{-1}$ at $15 \mathrm{~m}$ length. This result shows that the speed of operation is not linearly related to the distance covered during operation but could be affected by the quantity of weeds been operated on and also the topography and texture of the soil, since it was observed during the evaluation that the ridges within the area worked on were not of uniform dimension and height.

\begin{tabular}{|c|c|c|c|c|}
\hline Point & A & B & C & D \\
\hline Length $(\mathrm{m})$ & 5 & 5 & 5 & 5 \\
\hline Time $(\mathrm{sec})$ & 22.5 & 20.57 & 14.94 & 15.34 \\
\hline Speed $(\mathrm{m} / \mathrm{s})$ & 0.22 & 0.24 & 0.33 & 0.33 \\
\hline Length $(\mathrm{m})$ & 10 & 10 & 10 & 10 \\
\hline Time $(\mathrm{sec})$ & 40.66 & 44.68 & 45.32 & 43.18 \\
\hline Speed $(\mathrm{m} / \mathrm{s})$ & 0.25 & 0.22 & 0.22 & 0.23 \\
\hline Length $(\mathrm{m})$ & 15 & 15 & 15 & 15 \\
\hline Time $(\mathrm{sec})$ & 64.32 & 64.37 & 56.40 & 55.40 \\
\hline Speed $(\mathrm{m} / \mathrm{s})$ & 0.23 & 0.23 & 0.27 & 0.27 \\
\hline
\end{tabular}

Table 1: Determination of Speed in $\mathrm{Ms}^{-1}$

\subsection{Determination of Mechanical Damage}

Fig. 6 shows the effect of weeding time on mechanical damage, it illustrates that weeding time does not have a significant effect on plant damage as there is no linear relationship between plant damage and weeding time. Hence, it was deduced from our observation that damage to plant during weeding greatly depends on the skills, carefulness of the operator, inter and intra row spacing between the plant and the plant height. Moreover, the larger percent of the damaged crops were discovered to be plant with stunted growth and short height which was not easily noticed by the operator and the inconsistency in spacing between the plants also affected the manoeuvring of the machine thereby making the machine parts to cause bruise and breakage on some part of the cassava stem. 


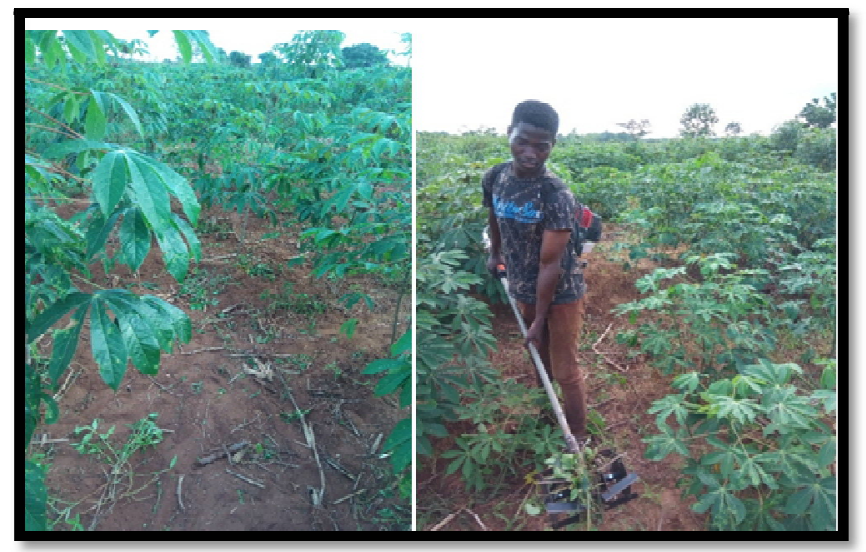

Figure 5: Feasibility Test of the Power Weeder

\begin{tabular}{|c|c|c|c|c|}
\hline PLOT & A & B & C & D \\
\hline Area (m ${ }^{2}$ ) & 5 & 5 & 5 & 5 \\
No. of plants before weeding & 24 & 15 & 25 & 30 \\
No of plants totally removed by the weeder & 1 & 2 & 0 & 5 \\
No of damaged plants & 3 & 2 & 0 & 0 \\
Time spent (min) & 9.36 & 7.20 & 7.40 & 8.53 \\
Mechanical damage (\%) & 16.7 & 26.7 & 0 & 16.7 \\
Mean (mechanical damage \%) & 15.02 & & & \\
\hline
\end{tabular}

Table 2: Determination of Mechanical Damage

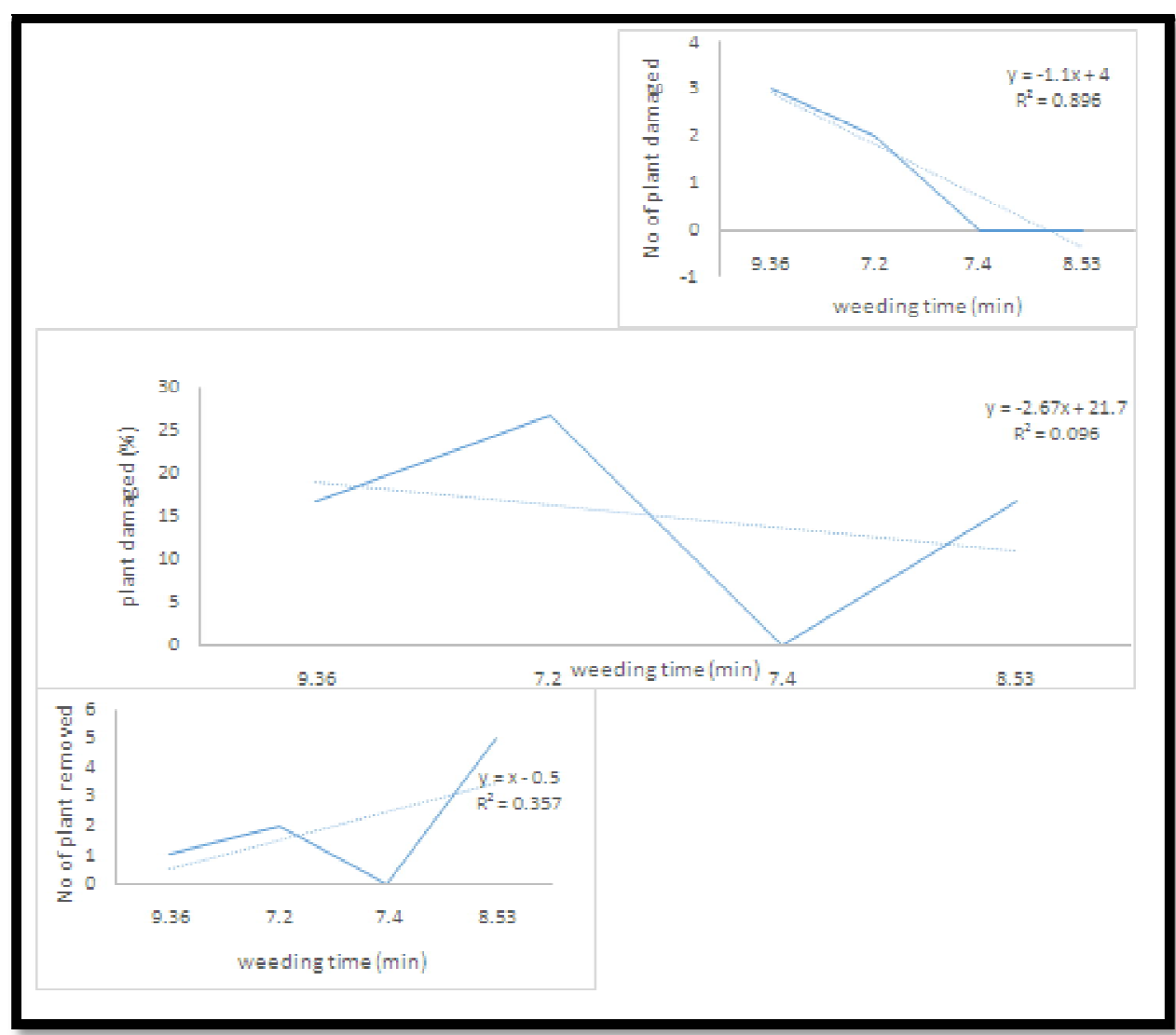

Figure 6: Mechanical Damage during Weeding

\section{3. Determination of Weeding Efficiency}

The lowest weeding efficiency of $86 \%$ and highest weeding efficiency of $94 \%$ was recorded during the testing on the $1 \mathrm{~m}^{2}$ plot which was replicated in triplicate. The average weeding efficiency of the machine was calculated to be $89 \%$. The efficiencies on the three $1 \mathrm{~m}^{2}$ plot is shown in table 3, Fig.7 shows that weeding index is not significantly dependent on the number of weeds present before weeding. 


\begin{tabular}{|c|c|c|c|}
\hline PLOT & E & F & G \\
\hline Area (m ${ }^{2}$ ) & 1 & 1 & 1 \\
No. of weeds before weeding & 64 & 69 & 52 \\
No of weeds after weeding & 4 & 10 & 7 \\
Weeding efficiency (\%) & 94 & 86 & 87 \\
Average weeding efficiency (\%) & 89 & & \\
\hline
\end{tabular}

Table 3: Determination of Weeding Efficiency

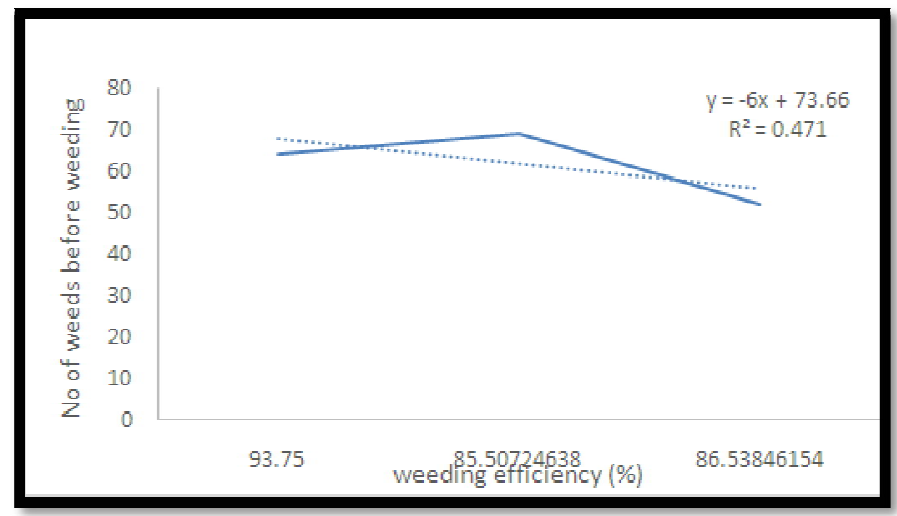

Figure 7: Weeding Efficiency and Number of Weeds Present before Weeding

\subsection{Theoretical Field Capacity}

The highest theoretical field capacity was obtained at $5 \mathrm{~m}$ length and 18.34 seconds (weeding time) while the lowest theoretical field capacity was obtained at $10 \mathrm{~m}$ length and 43.46 seconds.

\begin{tabular}{|c|c|c|c|c|c|}
\hline Distance (M) & Average Time (Sec) & $\begin{array}{c}\text { Average Speed } \\
\mathbf{( M / S )}\end{array}$ & $\begin{array}{c}\text { Speed In } \\
\mathbf{K m} / \mathbf{H r}\end{array}$ & $\begin{array}{c}\text { Width } \\
\mathbf{( M )}\end{array}$ & T.F.C(Hah-1) \\
\hline 5 & 18.34 & 0.28 & 1.008 & 0.32 & 0.0323 \\
\hline 10 & 43.46 & 0.23 & 0.828 & 0.32 & 0.0274 \\
\hline 15 & 60.12 & 0.25 & 0.9 & 0.32 & 0.0288 \\
\hline
\end{tabular}

Table 4: Theoretical Field Capacity

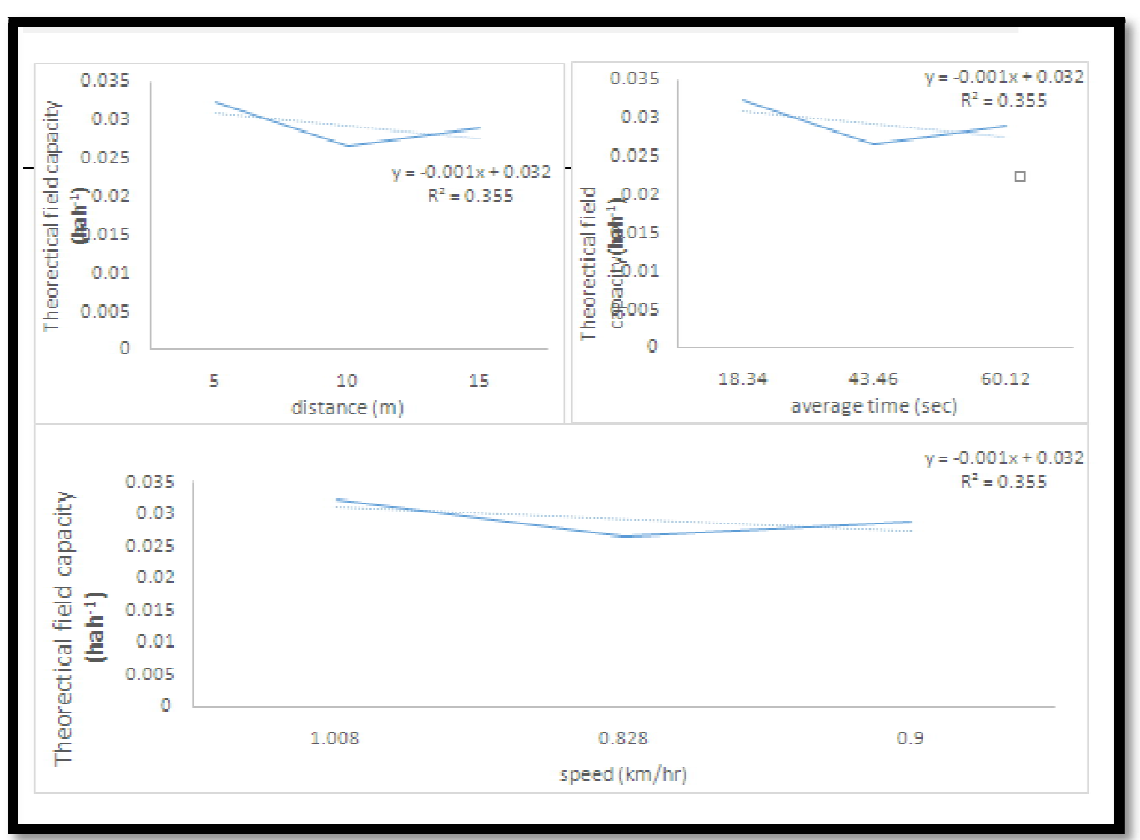

Figure 8: Effect of Time, Distance and Speed on Theoretical Field Capacity 


\begin{tabular}{|c|c|c|c|c|}
\hline Width (M) & T.F.C(Hah & -1) & Area Covered (M) & E.F.C (Hah \\
\hline $\mathbf{1})$ & Average Time (Sec) \\
\hline 0.32 & 0.032256 & 1.6 & 0.031407 & 18.34 \\
\hline 0.32 & 0.027496 & 3.2 & 0.026507 & 43.46 \\
\hline 0.32 & 0.0288 & 4.8 & 0.028743 & 60.12 \\
\hline
\end{tabular}

Table 5: Determination of Effective Field Capacity for Varying Distance

\begin{tabular}{|c|c|c|}
\hline Area Covered (M) & Time (Min) & Effective Field Capacity(Hah-1) \\
\hline 5 & 9.36 & 0.003205128 \\
\hline 5 & 7.2 & 0.004166667 \\
\hline 5 & 7.4 & 0.004054054 \\
\hline 5 & 8.53 & 0.003516999 \\
\hline
\end{tabular}

Table 6: Determination of Effective Field Capacity for $5 \mathrm{~m}^{2}$ Plots of Land

\subsection{Field Efficiency}

This is the ratio of effective field capacity to theoretical field capacity when expressed in percentage. Table7 shows that the highest field efficiency of $99.8 \%$ and lowest field efficiency of $96.4 \%$ was recorded during the evaluation process.

\begin{tabular}{|c|c|c|}
\hline $\begin{array}{c}\text { Theoretical Field Capacity } \\
\text { (Hah-1) }\end{array}$ & $\begin{array}{c}\text { Effective Field } \\
\text { Capacity (Hah }\end{array}$ & Field Efficiency (\%) \\
\hline 0.032256 & 0.031407 & 97.36719115 \\
\hline 0.027496 & 0.026507 & 96.40359687 \\
\hline 0.0288 & 0.028743 & 99.8003992 \\
mean & mean & mean \\
0.0295 & 0.0288 & 97.3333333 \\
\hline
\end{tabular}

Table 7: Determination of Field Efficiency

\subsection{Moisture Content and Bulk Density}

Soil moisture content, \% (db) is 18.00 , bulk density before weeding $(\mathrm{gm} / \mathrm{cc})$ is 1.31 and bulk density after weeding operation, $(\mathrm{gm} / \mathrm{cc})$ is 1.22 . This shows that the power weeder does not compact the soil but it pulverizes the soil.

\subsection{Fuel Consumption}

The machine fuel consumption is economical as it consumes $0.264 \mathrm{lhr}^{-1}$ and $77 \mathrm{lha}^{-1}$

\section{Conclusion and Recommendation}

\subsection{Conclusion}

The weeder was evaluated at Idogo farm settlement, Idogo road Ilaro community. On the $14^{\text {th }}$ of August 2018. The power weeder worked effectively and the following optimum performance parameter were recorded: Field capacity (99.8\%), Theoretical Field capacity $\left(0.0288 \mathrm{hah}^{-1}\right)$, effective field capacity $\left(0.0314 \mathrm{hah}^{-1}\right)$, weeding efficiency (94\%), plant damaged (26.7), speed of operation $(0.28 \mathrm{~m} / \mathrm{s})$. The weeder consumed $77 \mathrm{lha}^{-1}$ this implies the operational cost of the weeder, is economical.

\subsection{Recommendation}

Based on the evaluation result the following recommendation were made:

- The power weeder is recommended for small and medium scale farmers.

- The weeder can be used in a field with non-uniform inter and intra row spacing provided the plant are of uniform height and at least 33cm high.

- The weeder is recommended for weeding in a field with uniform inter and intra row spacing.

- The weeder should be operated by physically strong man

- The rotating shaft of the weeder's blade should be checked regularly to prevent clogging during operation.

- The weeder is recommended for use in a tilled farm land.

\section{References}

i. Biwas, H.S. (1984). Sustainable development of crop. International journal of plant science, vol 2; Pg 36.

ii. Chanakyan C. and Mohanty S.K. (2017). Performance evaluation of power operated wetland paddy weeder. International Journal of multidisciplinary research and development. Vol. 4, issue 10; pp 140-146.

iii. Khurmi, R.S. and Gupta, J.K. (2003). A text book of machine design. Eurasia Publishing House (Pvt) Ltd., Ram Nagar, New Delhi (INDIA).

iv. Rangasamy, K., Balasubramanian, M and K.R. Swaminathan. (1993). Evaluation of Power Weeder Performance. Agricultural Mechanization in Asia, Africa and Latin American,24(4): 16-18.

v. Saiful A.K.M., M.T. Islam., A.K.M. Lutfor Rahman and M.A. Rahman (2017). Performance evaluation of BRRI Power Weeder for low land rice cultivation. A scientific Journal of Krishi Foundation. 15(1): 40-48. 
vi. Vinod, K.K., (2002). Design, Development and Testing of Power Weeder Cum Secondary Tillage Implement. Department of Farm Machinery and Power, College of Agricultural Engineering, 10(3).

\section{Appendix}

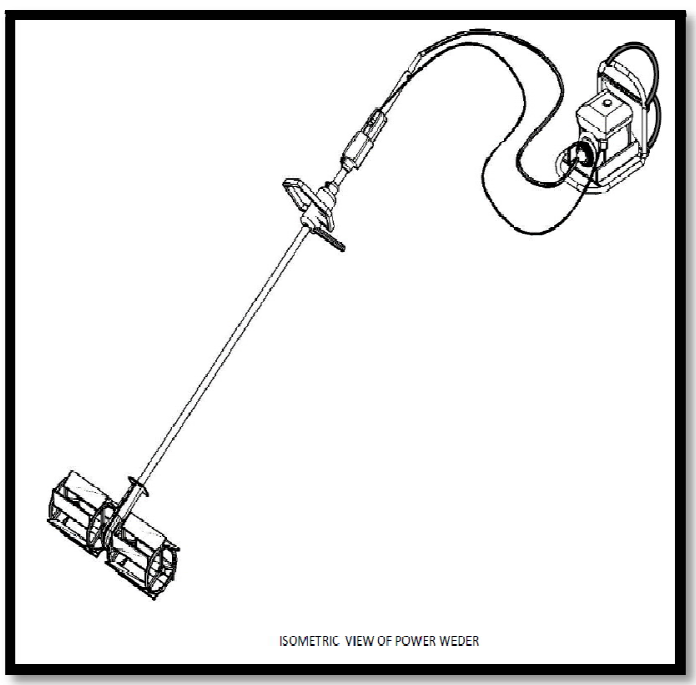

Figure 9

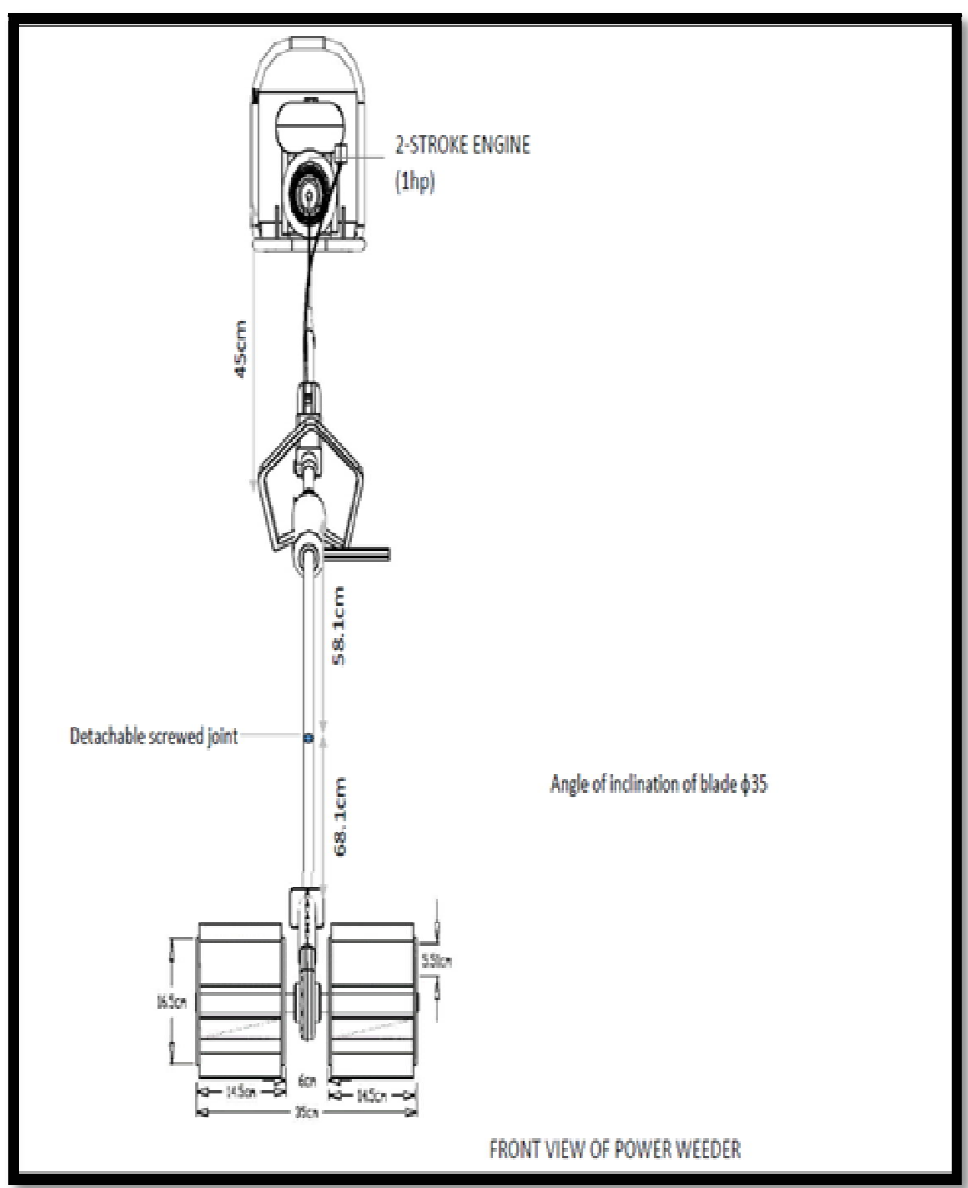

Figure 10 


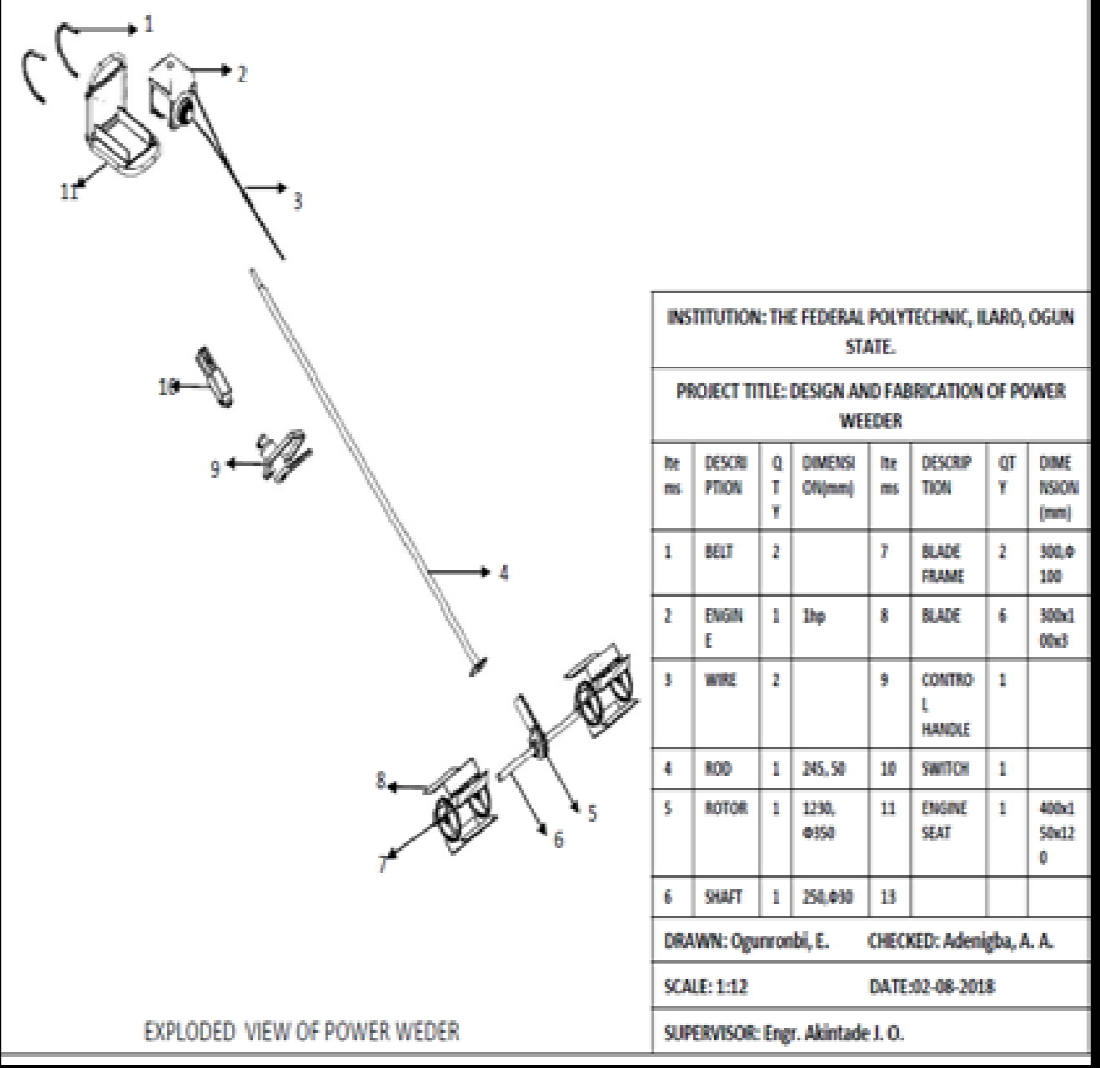

Figure 11

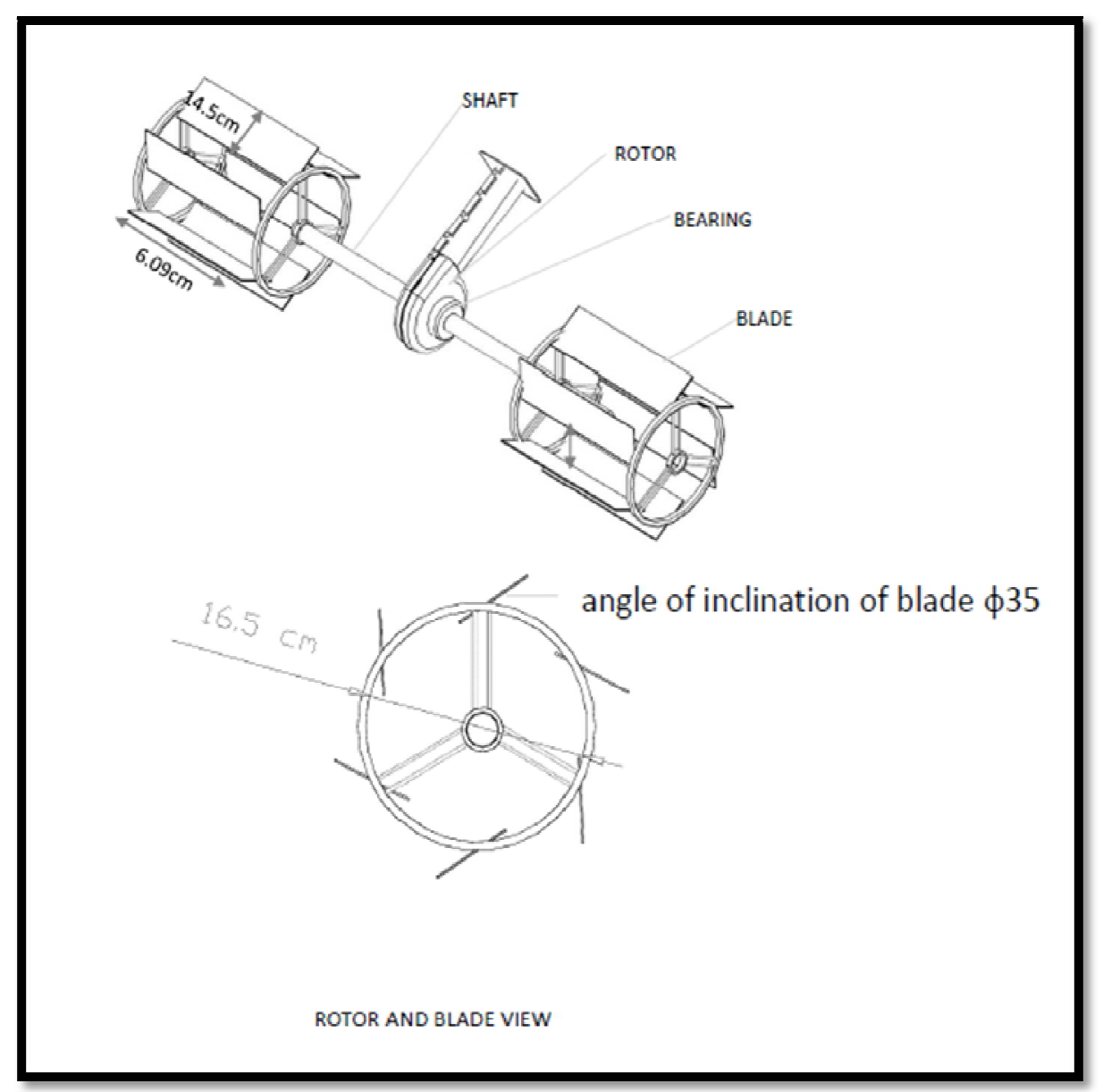

Figure 12 


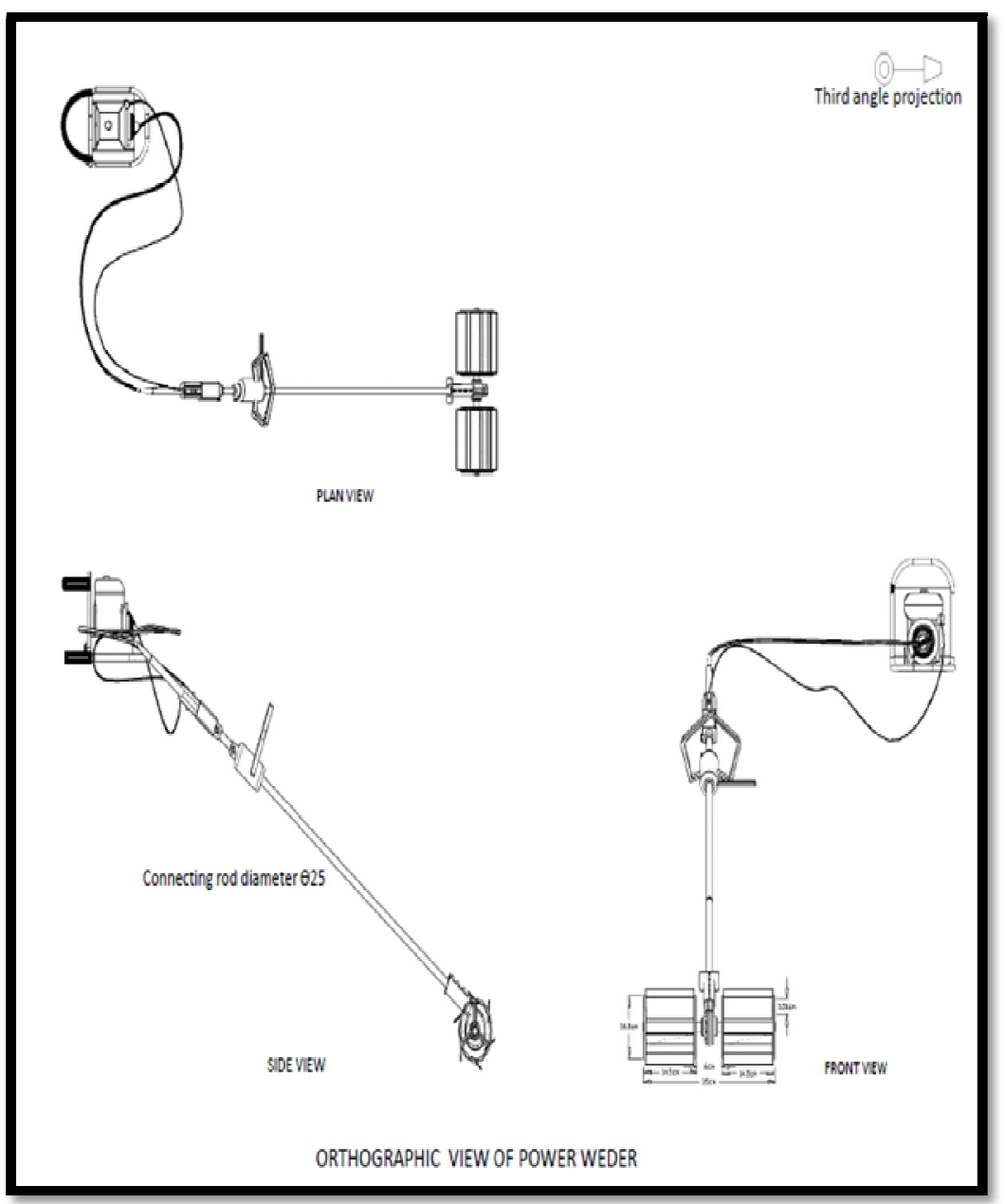

Figure 13

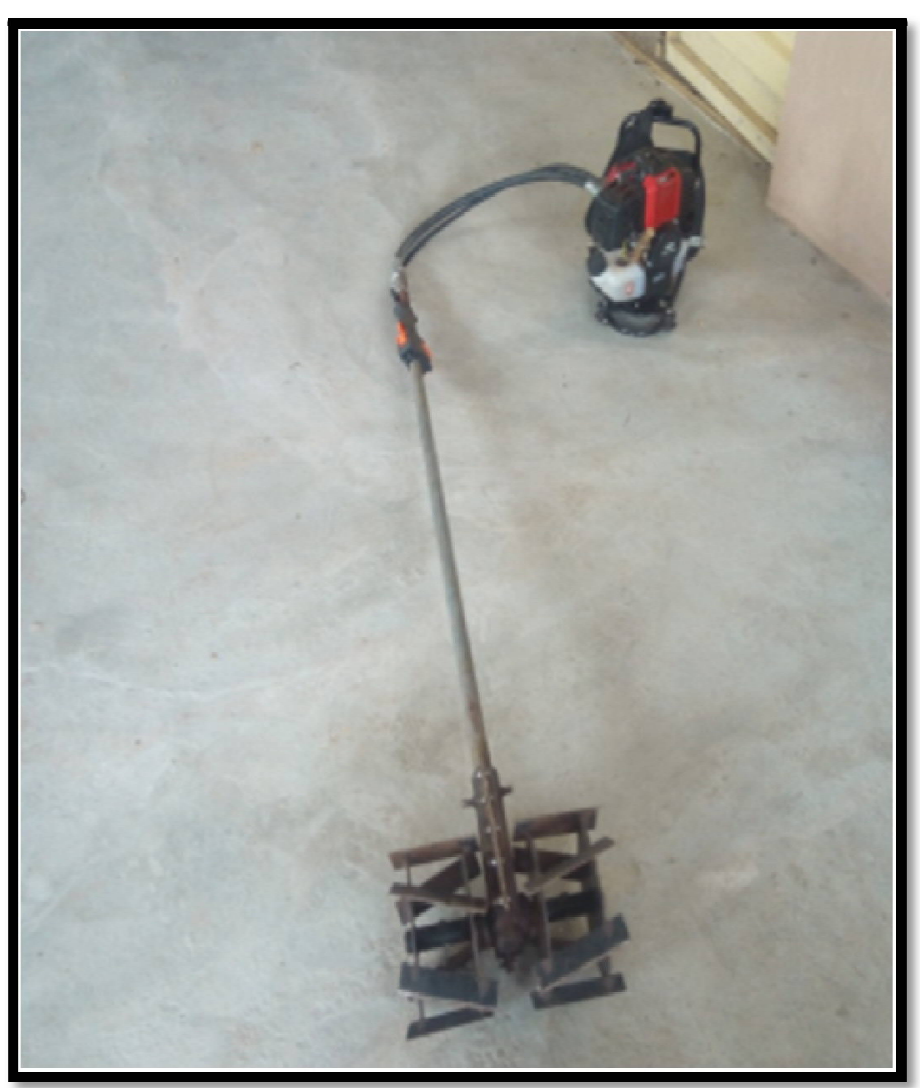

Figure 14 